Research article

Open Access

\title{
Increased production of soluble CTLA-4 in patients with spondylarthropathies correlates with disease activity
}

\author{
Éric Toussirot ${ }^{1,2,3 \star}$, Philippe Saas ${ }^{4 \star}$, Marina Deschamps ${ }^{4}$, Fabienne Pouthier ${ }^{5}$, Lucille Perrot ${ }^{3,4}$, \\ Sylvain Perruche ${ }^{4}$, Jacqueline Chabod ${ }^{5}$, Pierre Tiberghien ${ }^{4,5}$ and Daniel Wendling ${ }^{1,2}$
}

\author{
1Department of Rheumatology, University Hospital Jean Minjoz, Bd Fleming 25030 Besançon cedex, France \\ 2EA 3186 "Agents Pathogènes et Inflammation» University of Franche-Comté, IFR133, Place St Jacques, Besançon, France \\ ${ }^{3} \mathrm{ClC}$-Biotherapy 506, University Hospital St-Jacques, Place St Jacques, 25030 Besançon cedex, France \\ 4 INSERM UMR645, University of Franche-Comté, EFS Bourgogne Franche-Comté, Plateforme de Biomonitoring, CIC-Biotherapy 506, IFR133, Bd \\ Fleming, 25020 Besançon cedex, France \\ ${ }^{5}$ EFS Bourgogne Franche-Comté, Bd Fleming, 25020 Besançon cedex, France \\ ${ }^{*}$ Contributed equally \\ Corresponding author: Éric Toussirot, etoussirot@chu-besancon.fr \\ Received: 17 Dec 2008 Revisions requested: 3 Feb 2009 Revisions received: 6 Jun 2009 Accepted: 1 Jul 2009 Published: 1 Jul 2009 \\ Arthritis Research \& Therapy 2009, 11:R101 (doi:10.1186/ar2747) \\ This article is online at: http://arthritis-research.com/content/11/4/R101 \\ (c) 2009 Toussirot et al.; licensee BioMed Central Ltd. \\ This is an open access article distributed under the terms of the Creative Commons Attribution License (http://creativecommons.org/licenses/by/2.0), \\ which permits unrestricted use, distribution, and reproduction in any medium, provided the original work is properly cited.
}

\begin{abstract}
Introduction Spondylarthropathies $(\mathrm{SpA})$ are characterized by abnormal immune responses including $\mathrm{T}$ cell activation. Cytotoxic $T$ lymphocyte associated molecule-4 (CTLA-4) is involved in down-regulating immune responses. A soluble form of CTLA-4 (sCTLA-4), resulting from an alternative splicing, has been identified and was found increased in several autoimmune diseases. Here, we evaluated circulating levels of SCTLA-4 as a marker of immune dysregulation in SpA. Intracellular CTLA-4 and levels of $C T L A-4$ transcript expression in peripheral blood lymphocytes (PBL) were also studied.
\end{abstract}

Methods Sera from 165 patients with SpA were evaluated for sCTLA-4 measurements. Results were compared with those from 71 patients with rheumatoid arthritis (RA) and 88 healthy subjects. In 32 patients with SpA, 22 patients with RA and 15 healthy controls, we analyzed the intracellular CTLA-4 expression in CD4+ T cells, CD8+ T cells, activated (HLADR+Foxp3-) CD4+ T cells, CD4+ regulatory (CD25+Foxp3+) $\mathrm{T}$ cells and in CD3 negative cells by flow cytometry. Expression of the full length (coding for membrane CTLA-4) and spliced form (coding for sCTLA-4) of CTLA-4 transcripts in PBL were analyzed by quantitative real-time polymerase chain reaction (QRT-PCR).

Results High levels of sCTLA-4 were found in the SpA group compared to the RA group and healthy controls $(P<0.0001)$. Soluble CTLA-4 serum levels strongly correlated with clinical index of disease activity BASDAI $(r=0.42, P<0.0001)$ and Creactive protein (CRP) levels $(r=0.17, P=0.037)$. In contrast to RA patients, SpA patients did not exhibit changes in intracellular CTLA-4 expression in the different PBL subsets tested. Finally, the SpA group showed a preferential expression of the spliced CTLA-4 mRNA $(P=0.0014)$ in PBL.

Conclusions SpA patients exhibit high levels of circulating sCTLA-4 that may result from an alternative splicing of CTLA-4 transcripts. This may influence immune activation and regulation in $\mathrm{SpA}$.

\section{Introduction}

Seronegative spondylarthropathies $(\mathrm{SpA})$ are chronic inflammatory diseases mainly affecting the axial skeleton and leading to progressive spinal ankylosis. Peripheral arthritis and enthesopathic lesions are also observed. The prototype of the disease is ankylosing spondylitis (AS), and other clinical features include reactive arthritis, psoriatic arthritis, enteropathic arthritis and undifferentiated SpA [1]. All these diseases have

ANOVA: analysis of variance; APC: antigen presenting cells; BASDAl: Bath Ankylosing Spondylitis Disease Activity Index; BASFI: Bath Ankylosing Spondylitis Functional Index; CRP: C-reactive protein; CTLA-4: cytotoxic T lymphocyte antigen-4; EDTA: ethylenediaminetetraacetic acid; ELISA: enzyme-linked immunosorbent assay; ESR: erythrocyte sedimentation rate; FITC: fluorescein isothiocyanate; HAQ: Health Assessment Questionnaire; HLA: Histocompatibility Leukocyte Antigen; NSAIDs: non-steroidal anti-inflammatory drugs; PBL: peripheral blood lymphocytes; Pe-cy 7: phycoerythrin-cyanin 7; RA: rheumatoid arthritis; sCTLA-4: soluble cytotoxic T lymphocyte antigen-4; SEM: standard error of the mean; SLE: systemic lupus erythematosus; SpA: spondylarthropathies; TNF: tumor necrosis factor; Treg: regulatory T cells. 
a common genetic background, namely the Histocompatibility Leukocyte Antigen (HLA) Class I B27, which is strongly associated to SpA and particularly to AS.

The pathophysiology of these diseases is not completely understood, but it is believed that the genetic component is directly involved as demonstrated by transgenic rats expressing human HLA-B27 [2]. Environmental factors also play a role in $\mathrm{SpA}$, particularly bacterial antigens from the gut or the genitourinary tract [3]. Different cellular subsets are observed in the joints or entheseal structures of SpA including macrophages and neutrophils, and also CD8+ and CD4+ T lymphocytes [4,5]. It has been suggested that aberrant immune response occurs in $\mathrm{SpA}$ or that $\mathrm{SpA}$ results from molecular mimicry. It is thought that unregulated CD8+ and/or CD4+ T cell responses to bacterial or self antigens participate in SpA pathophysiology and that both responses involve the HLAB27 molecule [6]. Indeed, CD4+T cells are required for the development of the disease in the animal model of transgenic rat for human HLA-B27.

CD28 expressed on T cells and its ligands, CD80 and CD86, present on the antigen presenting cells (APC) are the prototypical costimulatory molecules [7]. Cytotoxic T lymphocyte associated molecule-4 (CTLA-4 or CD152) is expressed on T cells after activation, but it is constitutively expressed by CD4+CD25+ regulatory cells (Treg) [8]. This molecule is homologous to CD28 and binds to CD80 and CD86 with a higher affinity. Membrane bound CTLA-4 acts by interfering with CD28/CD80-CD86 interactions by competitive binding and also by mediating a negative signal interfering with $T$ cell receptor stimulation [9]. Thus, CTLA-4 triggering leads to a down regulation of $\mathrm{T}$ cell response, induction of apoptosis and/or immunological anergy [7]. On the other hand, CTLA-4 is absolutely required for the suppressive function of naturally occurring FoxP3+ Treg, at least in mice [10]. In addition to CD4+ and CD8+ T cells, B cells also express CTLA-4 [8].

A soluble form of CTLA-4 (sCTLA-4) has also been described $[11,12]$. This soluble molecule results from an alternative transcript of the CTLA-4 gene, which lacks the third exon encoding the transmembrane domain of the CTLA-4 molecule $[11,12]$. This soluble form, detected in CD4+ and CD8+ T cells, B cells and lymphoid organs [8], is able to bind CD80 and CD86. Recent data showed the increase of sCTLA-4 in the serum of patients with various autoimmune diseases, such as thyroiditis [13], myasthenia gravis [14], systemic lupus erythematosus (SLE) [15,16], and systemic sclerosis [17]. It has been suggested that SCTLA-4 may interfere with normal immune response, favoring autoreactivity in these conditions [11]. In addition, genetic studies revealed that there is an association between CTLA-4 gene polymorphism and susceptibility to autoimmune diseases [18].
Abnormal T cell activation is observed in SpA, suggesting a possible defect of lymphocyte inhibitory molecules. Thus, here, we investigated the serum levels of sCTLA-4 in a large cohort of patients with SpA. Then, we analyzed the cellular expression of CTLA-4 on different peripheral blood lymphocyte (PBL) subsets, as well as CTLA-4 transcripts in PBL. The results obtained in SpA patients were compared with those obtained in patients with rheumatoid arthritis (RA).

\section{Materials and methods \\ Patients with spondylarthropathy}

We enrolled 165 consecutive patients who met the European Spondylarthropathy Study group criteria for SpA [19] and were receiving follow-up at our department (Rheumatology Department, Besançon, France). Clinical assessment included the following demographic data: age, sex, disease duration, and extra-articular manifestations (uveitis). The clinical activity was evaluated using the Bath Ankylosing Spondylitis Disease Activity Index (BASDAI) [20] and the functional score Bath Ankylosing Spondylitis Functional Index (BASFI) [21]. Erythrocyte sedimentation rate (ESR), and $C$ reactive protein (CRP) levels were used as laboratory parameters to assess inflammation. Biologic assessment also included HLAB27 determination. All the patients received non-steroidal antiinflammatory drugs (NSAIDs) and some of them had a secondline treatment such as sulfasalazine $(n=23)$ or methotrexate $(n=10)$. A limited number of patients had corticosteroids at a low dosage (daily prednisolone $\leq 10 \mathrm{mg} ; \mathrm{n}=8$ ). In order to avoid anti-TNF- $\alpha$ agent as a confounding factor, patients under or who had previously received anti-TNF- $\alpha$ agent were excluded from this study.

\section{Patients with rheumatoid arthritis}

Seventy-one patients with RA meeting 1987 American College of Rheumatology criteria [22] were included for purposes of comparison. For each of these patients, the following data were recorded: age; sex; disease duration; extra-articular manifestations (subcutaneous nodules, vasculitis, sicca syndrome, pulmonary, or cardiac involvement); tender and swollen joint counts; the Health Assessment Questionnaire (HAQ) score; the ESR and CRP levels; and whether tests were positive for rheumatoid factors.

\section{Patients with systemic lupus erythematosus}

In order to have another comparative group (with previously determined elevated serum sCTLA-4 levels) [15,16], 14 patients with SLE (13 females, 1 male, mean age $44.1 \pm 5.5$ years) responding to the 1982 revised American Rheumatism Association criteria [23] were also recruited.

\section{Control subjects}

The control group consisted of 88 healthy subjects without inflammatory conditions (platelets donors). HLA class I antigen determination was available in this group. As most of the patients with SpA were HLA-B27 positive and the frequency 
of this antigen in the normal population is around $8 \%$, we selected 24 HLA-B27-positive subjects from the platelet donors for this control group.

All the patients and control subjects gave their informed consent to participate in the study according to the Helsinki declaration and our study protocol was approved by our local ethics committee (comité d'éthique clinique du $\mathrm{CHU}$ de Besançon).

\section{Determination of circulating soluble CTLA-4}

Serum concentrations of sCTLA-4 in patients with SpA, RA, or SLE and control subjects were determined by ELISA using reagent kits for human SCTLA-4 (AbCys, Paris, France) according to the manufacturer's instructions.

\section{Flow cytometric analysis of intracellular expression of CTLA-4 on Iymphocyte subsets}

Absolute numbers of blood T cells, CD4+ and CD8+ T cells were determined by single platform flow cytometry using the TetraCXP ${ }^{\circledR}$ method, Flow-Count fluorospheres, and FC500 ${ }^{\circledR}$ cytometer (Beckman Coulter, Villepinte, France) according to the manufacturer's recommendations [24]. CTLA-4 is not expressed on human naive resting $\mathrm{T}$ cells and is only expressed after activation on the surface at low levels (less than $10 \%$ of total CTLA-4) [8], so we decided to evaluate intracellular CTLA-4 expression in fixed and permeabilized lymphocytes to appreciate CTLA-4 expression in different lymphocyte subsets. Staining was performed on ethylenediaminetetraacetic acid (EDTA) venous blood samples after red blood cell lysis. Cells were stained with allophycocyanin-conjugated CD3, phycoerythrin-cyanin 7 (PE-Cy7)conjugated CD4, fluorescein isothiocyanate (FITC)-conjugated CD8 antibodies (Beckman Coulter, Villepinte, France), then fixed, permeabilized and stained again using PE-conjugated anti-CTLA-4 (anti-CD152) antibody (Beckman Coulter, Villepinte, France) before being analyzed using FACS Canto $\|{ }^{\circledR}$ cytometer (BD Biosciences, Le Pont de Claix, France). The same experiments were also performed using conjugated antiHLA-DR, FITC-conjugated anti-CD25, PE Texas Red (ECD) conjugated anti-CD69 (Beckman Coulter, Villepinte, France) or conjugated anti-FoxP3 (clone PCH101, eBioscience, San Diego, CA, USA) [25] antibodies. Intracellular expression of CTLA-4 was examined in CD3+ T cells, in activated (HLADR+) CD4+ T cells, in early activated (CD69+) CD4+ T cells, and in (CD25+ FoxP3+) CD4 + Treg. Non-specific staining was determined using labeled irrelevant control antibodies from the same antibody providers. Intracellular CTLA-4 analysis was performed in 32 SpA patients, 22 RA patients, and 15 healthy controls. These patients and healthy donors were randomly selected and corresponded to consecutive patients (samples were collected between August 2006 and April 2007).

\section{Quantification of full length and spliced CTLA-4 transcripts in peripheral blood mononuclear cells}

The human CTLA-4 gene contains four exons. The full length CTLA-4 mRNA contains these four exons, encoding the CTLA-4 molecule expressed at the cell membrane [9]. sCTLA4 is generated by alternatively spliced mRNA. This splicing event deletes the entire transmembrane region of the CTLA-4 molecule (corresponding to exon 3 ). Thus, the spliced CTLA4 mRNA contains only three exons, encoding for the soluble form of CTLA-4 [11]. Total RNA was extracted from $3 \times 10^{6}$ of cells using the RNeasy ${ }^{\circledR}$ Blood mini kit (QIAGEN, Courtaboeuf, France) according to the manufacturer's instructions, and reverse transcribed using random hexamers and M-MLV reverse transcriptase (Life Technologies, Rockville, MD, USA) to use as a template for quantitative real-time polymerase chain reaction (QRT-PCR). QRT-PCR reactions were performed in duplicate using gene-specific probes and a universal master mix (Applied Biosystems, Courtaboeuf, France) on an iCycler iQ thermocycler (Bio-Rad Laboratories, Marnes-laCoquette, France). For full length CTLA-4 transcript analysis, gene-specific primers and bi-fluorescent hydrolysis probes were obtained from Assays-on-DemandTM gene expression products (\#Hs99999101_m1; Applied Biosystems, Courtaboeuf, France). Expression of spliced CTLA-4 transcripts was analyzed using the following primer pair designed by ourselves (sense, anti-sense and probe respectively):

5'-CATCTGCAAGGTGGAGCTCAT-3', 5'-GGCTTCTTTTCTTTAGCAATTACATAAATC-3', and 5'-FAM-ACCGCCATACTACCTGGGCATAGGCA-TAMRA3'. Analysis was carried out using the $\Delta \Delta \mathrm{Ct}$ method [26] with the pool of 15 healthy donor PBL samples as a calibrator and $18 S$ as a housekeeping reference gene. Target gene expression was expressed as a fold change compared with healthy donor PBL.

\section{Statistical analysis}

Results were expressed as mean \pm standard error of the mean (SEM; range). Only non-parametric tests were used. Statistical analysis between the three groups (healthy controls, SpA, and RA) involved non-parametric analysis of variance (ANOVA) using the Kruskal-Wallis test. This test was used to compare age, circulating sCTLA-4 levels, T cell subsets, and intracellular CTLA-4 expression. When a significant difference was found between the three groups, a two-group analysis was performed a second time ( $\mathrm{SpA}$ vs controls, RA vs controls and SpA vs RA) using the Mann-Whitney $U$-test. This test was also used to compare variables (disease duration, ESR, CRP) between SpA and RA patients and between SLE patients and healthy controls (sCTLA-4). Qualitative data (sex) were analyzed using the chi-squared test. Wilcoxon test was used to compare the relative expression of the full length and the spliced form of CTLA-4 transcripts in patients with $\mathrm{SpA}$ and in patients with RA. Spearman's $r$-test was used to calculate correlations between SCTLA-4 and indices of disease activity of SpA or RA, and between CTLA-4 transcripts and 
Table 1

Clinical characteristics and laboratory features of patients with SpA or RA and healthy controls

\begin{tabular}{|c|c|c|c|c|}
\hline & $\left.\begin{array}{c}\mathrm{HC} \\
(\mathrm{n}=\mathbf{8}\end{array}\right)$ & $\begin{array}{c}\text { SpA } \\
(n=165)\end{array}$ & $\begin{array}{c}\mathrm{RA} \\
(\mathrm{n}=71)\end{array}$ & $\mathbf{P}$ \\
\hline Age (years) & $\begin{array}{l}44.4 \pm 0.8 \\
(20 \text { to } 62)\end{array}$ & $\begin{array}{l}42.9 \pm 1.1 \\
(18 \text { to } 75)\end{array}$ & $\begin{array}{l}59.1 \pm 1.4 \\
(19 \text { to } 80)\end{array}$ & $\begin{array}{c}<0.0001(\mathrm{KW}) \\
\text { SpA vs HC }(\mathrm{MW}): P=0.28 \\
\text { RA vs SpA and RA vs } \mathrm{HC}(\mathrm{MW}): P< \\
0.0001\end{array}$ \\
\hline Sex & $56 \mathrm{M} / 16 \mathrm{~F}$ & $121 \mathrm{M} / 44 \mathrm{~F}$ & $27 \mathrm{M} / 44 \mathrm{~F}$ & $\begin{array}{c}\text { SpA vs HC vs RA: } P<0.0001\left(\chi^{2}\right) \\
\text { SpA vs HC: } P=0.9 \\
\text { RA vs SpA and RA vs HC: } P<0.0001\left(\chi^{2}\right)\end{array}$ \\
\hline Disease duration (years) & & $\begin{array}{c}9.2 \pm 0.6 \\
(0.5 \text { to } 35)\end{array}$ & $10.2 \pm 1.1(0.5$ to 40$)$ & $0.5(\mathrm{MW})$ \\
\hline Extra-articular manifestations (\%) & & $35 / 165(21)$ & $26 / 71(36.6)$ & \\
\hline Peripheral arthritis (\%) & & $46 / 165(27.8)$ & & \\
\hline BASDAI ( 0 to 100$)$ & & $\begin{array}{l}35.9 \pm 2.2 \\
(0.4 \text { to } 94)\end{array}$ & & \\
\hline BASFI (0 to 100$)$ & & $\begin{array}{l}41.2 \pm 2.9 \\
(0 \text { to } 92)\end{array}$ & & \\
\hline Swollen joint count (0 to 28 ) & & & $7.2 \pm 0.8(0$ to 22$)$ & \\
\hline Tender joint count ( 0 to 28 ) & & & $4.7 \pm 0.8(0$ to 28$)$ & \\
\hline $\mathrm{HAQ}(0$ to 3$)$ & & & $1.5 \pm 0.1(0$ to 3$)$ & \\
\hline HLA-B27 (\%) & & $145(87.8)$ & & \\
\hline Rheumatoid factors (\%) & & & $64 / 71(90)$ & \\
\hline $\operatorname{ESR}(\mathrm{mm} / \mathrm{h})$ & & $28.2 \pm 2.1(1$ to 163$)$ & $30.3 \pm 3.1$ ( 1 to 125$)$ & $0.3(\mathrm{MW})$ \\
\hline $\mathrm{CRP}(\mathrm{mg} / \mathrm{l})$ & & $25.1 \pm 3.2(0$ to 350$)$ & $22.3 \pm 3.5$ ( 1 to 132$)$ & $0.8(\mathrm{MW})$ \\
\hline
\end{tabular}

Results are expressed as mean \pm standard error of the mean (range). The Kruskal-Wallis test was used to compare age, disease duration, ESR, and CRP in the three groups. Then, Mann-Whitney $U$-test was used to calculate the exact $P$ values between two groups.

$\mathrm{BASDAI}=$ Bath Ankylosing Spondylitis Disease Activity Index; BASFI = Bath Ankylosing Spondylitis Functional Index; CRP = C-reactive protein; $\mathrm{ESR}=$ erythrocyte sedimentation rate; $\mathrm{HAQ}=$ Health Assessment Questionnaire; $\mathrm{HC}=$ healthy controls; $\mathrm{HLA}=$ Histocompatibility Leukocyte Antigen; KW = Kruskal-Wallis; MW = Mann-Whitney; NS = not significant; RA = rheumatoid arthritis; $\mathrm{SpA}=$ spondylarthropathie; $\chi^{2}=$ chisquared test.

sCTLA-4 in patients with SpA. Values of $P$ less than 0.05 were considered significant.

\section{Results \\ Study population}

The demographic, clinical characteristics, and laboratory features of the patients with SpA, patients with RA and healthy controls (platelet donors) are reported in Table 1. Of the 165 patients with SpA, 117 had AS, 7 had reactive arthritis, 5 had psoriatic arthritis, 5 had enteropathic arthritis, and 31 had undifferentiated SpA. At the time of evaluation, extra-articular manifestations were present in $21 \%$ and peripheral arthritis in $27.8 \%$ of patients with SpA. The HLA-B27 antigen was detected in $87.8 \%$ of patients. Among RA patients, $36.6 \%$ had extra-articular organ involvement.

The three groups (SpA, RA, healthy controls) differed regarding age $(P<0.0001)$ and pairwise tests showed that the patients with RA were older compared with the patients with SpA or healthy controls $(P<0.0001)$. However, age was similar in the SpA group and the control group $(P=0.28)$. The proportion of female patients was higher in the RA group than in the SpA and control groups $(P<0.0001)$, whereas the sex ratio was the same in the SpA and control subjects $(P=0.9)$. No differences were found between SpA and RA for disease duration, ESR, or CRP levels (all $P>0.05$ ).

\section{Analysis of circulating SCTLA-4}

Serum sCTLA-4 levels were significantly higher in the SpA group (3.66 $\pm 0.3 \mathrm{ng} / \mathrm{ml}, 1$ to 22.7 ) compared with the RA group ( $2.25 \pm 0.4 \mathrm{ng} / \mathrm{ml}, 0$ to 15.7$)$ or the control group (0.25 $\pm 0.1 \mathrm{ng} / \mathrm{ml}, 0$ to 3.4 ; Kruskal-Wallis: $P<0.0001)$. Serum sCTLA-4 levels were also found higher in patients with SLE $(19.58 \pm 2.7 \mathrm{ng} / \mathrm{ml}, 5.9$ to 41$)$ compared with healthy controls (Mann-Whitney $P<0.0001$ ) or compared to patients with SpA or RA (Mann-Whitney $P<0.0001$ ). Both SpA and RA patients had higher SCTLA-4 values compared with controls (Mann-Whitney $P<0.0001$ and $P=0.001$, respectively), whereas sCTLA-4 levels remained higher in the SpA group compared with RA $(P<0.0001$; Figure 1). 
Figure 1

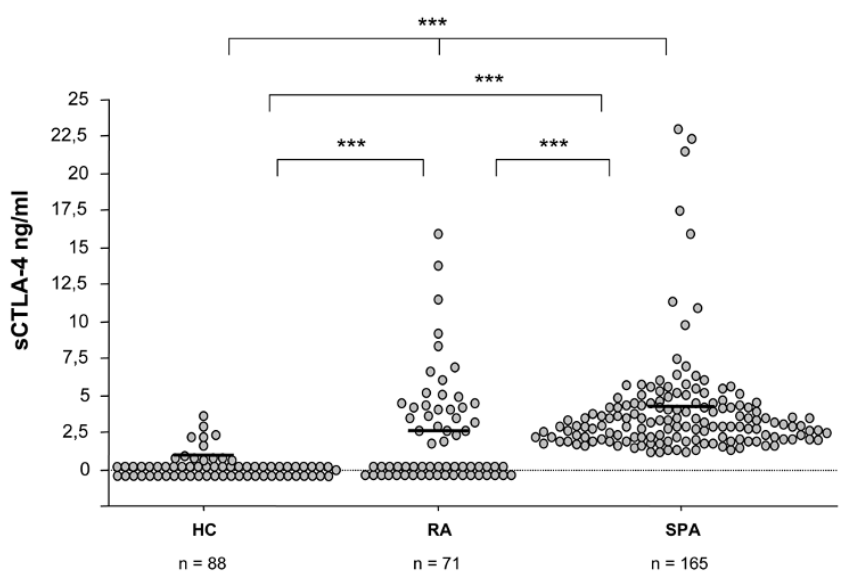

Serum concentrations of soluble Cytotoxic T Lymphocyte Antigen- 4 (sCTLA-4) in patients with spondylarthropathies $(\mathrm{SpA}, \mathrm{n}=165)$, with rheumatoid arthritis (RA, $n=71$ ) and healthy controls $(H C, n=88)$. Circulating sCTLA-4 was measured by ELISA, as described in the Material $\&$ Methods section. Horizontal lines represent means ${ }^{* \star \star}: P<0.005$; statistical tests and exact $p$ values are given in the Result section).

In the SpA group, serum sCTLA-4 correlated with BASDAI $(r$ $=0.42, P<0.0001$; Figure 2$)$ and $\mathrm{CRP}(r=0.17, P=0.037)$ but not with ESR, BASFI, age, or disease duration (all $P>$ 0.05). Serum sCTLA-4 levels were not influenced by the expression of the HLA-B27 antigen, the presence of extraarticular disease, or peripheral arthritis (all $P>0.05$ ), whereas male patients had higher SCTLA-4 than female patients (MannWhitney: $3.97 \pm 0.3,1$ to 22.7 ; vs $2.84 \pm 0.39,1$ to $17.3 \mathrm{ng} /$ $\mathrm{ml} P=0.02)$. In addition, age was not correlated with serum sCTLA-4 levels in the different groups of subjects (all $P>$ 0.05).

In the RA group, sCTLA-4 levels were correlated with swollen joint count $(r=-0.25, P=0.04)$ but not with laboratory parameters exploring inflammation (ESR and CRP), HAQ score, and tender joint score (all $P>0.05$ ).

Finally, in normal subjects, we did not observe any significant differences in serum SCTLA-4 levels between male and female subjects or between HLA-B27-positive and HLA-B27-negative subjects (all $P>0.05$ ).

To better understand this increase in circulating sCTLA- 4 in patients with $\mathrm{SpA}$, we then evaluated intracellular CTLA-4 expression. This analysis was performed in a representative number of patients and controls (i.e., 32 patients with SpA, 22 patients with RA, and 15 healthy controls).

\section{Analysis of blood lymphocyte subsets}

Before analysis of intracellular CTLA-4 expression in lymphocyte subsets, we first compared absolute numbers of circulating CD3+, CD4+, and CD8+ T cells in the SpA group, in the RA group, and in healthy volunteers involved in this analy-
Figure 2

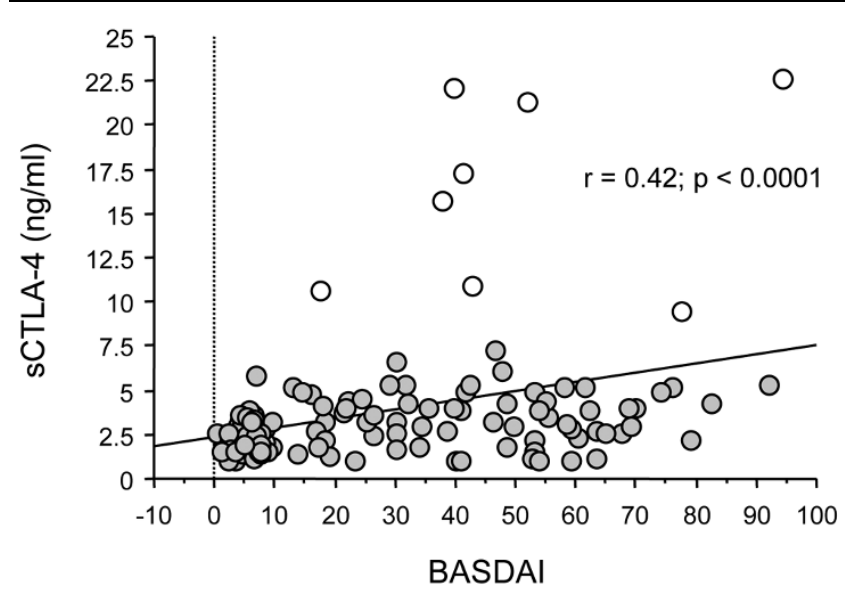

Correlation between soluble Cytotoxic T Lymphocyte Antigen- 4 (sCTLA-4) and clinical index of disease activity Bath Ankylosing Spondylitis Disease Activity Index in 165 patients with spondylarthropathies. The Bath Ankylosing Spondylitis Disease Activity Index (BASDAI) was evaluated as described in [19]. The statistical test used was Spearman's $r$ test. When the eight extreme values (white circles) are not considered for correlation analysis, a significant correlation between sCTLA-4 and BASDAl score is still observed: (Spearman's test: $r=$ $0.382, P<0.0001)$.

sis. The three groups differed significantly regarding the number of CD3+ and CD8+ T cells ( $P \leq 0.005$; Table 2). Indeed, RA patients had lower absolute numbers of CD3+ and CD8+ T cells compared with healthy controls or patients with SpA ( $P<0.01$ for each test). No difference in CD3+ T cells was observed between SpA patients and healthy controls, while CD8+ T cells were found to be lower in SpA, a result that was just near the significant level $(P=0.051)$.

We then examined the percentage of circulating activated CD4+ T cells and Treg in the three studied groups. No difference was observed between these three groups for activated CD4+ T cells or for Treg (all $P>0.05$; Table 2).

\section{Analysis of intracellular CTLA-4 expression in T cell subsets}

As shown in Table 2 and Figure 3, a significant difference was observed in the percentage of cells positive for intracellular CTLA-4 in CD4+ T cells, Treg, non T cells (CD3-negative cells in the lymphocyte gate, as assessed by flow cytometry; this presumably corresponds to $\mathrm{B}$ cells rather than natural killer cells [8]) and in the total lymphocyte gate between the three groups $(P<0.01$ for each test), while no similar difference was found for activated CD4+ T cells or CD8+ T cells. However, SpA patients and healthy controls did not differ with regard to intracellular CTLA-4 in all these distinct lymphocyte subsets (all $P>0.05$ ). Conversely, RA patients had lower intracellular CTLA-4 expression in CD4+ T cells and Treg compared with healthy controls or patients with $\mathrm{SpA}$ (all $P<$ 0.05). The expression of intracellular CTLA-4 in CD3 negative cells (presumably $B$ cells) was found to be higher in RA 
Table 2

Absolute number of circulating CD3+ T cells, CD4+ T cells, CD8+ T cells, percentage ofactivated CD4+ T cells, regulatory CD4+ T cells (Treg) and percentage of cells expressing intracellular CTLA-4 in healthy controls, patients with Spondylarthropathies and rheumatoid arthritis

\begin{tabular}{|c|c|c|c|c|}
\hline & $\begin{array}{l}\text { Healthy controls } \\
\quad(n=15)\end{array}$ & $\begin{array}{l}\text { Spondylarthropathies } \\
\qquad(\mathrm{n}=32)\end{array}$ & $\begin{array}{l}\text { Rheumatoid arthritis } \\
(\mathrm{n}=22)\end{array}$ & $P$ \\
\hline CD3+ T cells $\left(/ \mathrm{mm}^{3}\right)$ & $\begin{array}{c}1397 \pm 79 \\
(925 \text { to } 1806)\end{array}$ & $\begin{array}{l}1360 \pm 80.8 \\
(622 \text { to } 2681)\end{array}$ & $\begin{array}{l}1129 \pm 140 \\
(336 \text { to } 3024)\end{array}$ & $\begin{array}{c}0.005(\mathrm{KW}) \\
\text { RA vs HC } 0.004(\mathrm{MW}) \\
\text { SpA vs HC NS } \\
\text { SpA vs RA } 0.007(\mathrm{MW})\end{array}$ \\
\hline CD4+ T cells $\left(/ \mathrm{mm}^{3}\right)$ & $\begin{array}{c}817 \pm 45 \\
(449 \text { to } 1024)\end{array}$ & $\begin{array}{c}875 \pm 49.5 \\
(391 \text { to } 1699)\end{array}$ & $\begin{array}{c}804 \pm 102 \\
(239 \text { to } 2306)\end{array}$ & NS \\
\hline CD8+ T cells $\left(/ \mathrm{mm}^{3}\right)$ & $\begin{array}{c}573 \pm 47 \\
(379 \text { to } 860)\end{array}$ & $\begin{array}{l}457 \pm 39.6 \\
(130 \text { to } 979)\end{array}$ & $\begin{array}{c}326 \pm 52 \\
(72 \text { to } 1260)\end{array}$ & $\begin{array}{c}0.0006(\mathrm{KW}) \\
\text { RA vs HC } 0.0007(\mathrm{MW}) \\
\text { SpA vs HC } 0.051 \\
\text { RA vs SpA } 0.006(\mathrm{MW})\end{array}$ \\
\hline $\begin{array}{l}\text { HLA-DR+ Foxp3- } \\
\text { CD4+ T cells } \\
\text { (\% of CD4+ T cells) }\end{array}$ & $\begin{array}{l}16.6 \pm 5.53 \\
\quad(5 \text { to } 70)\end{array}$ & $\begin{array}{l}22.03 \pm 4.56 \\
\quad(4 \text { to } 100)\end{array}$ & $\begin{array}{l}12.14 \pm 1.29 \\
(5 \text { to } 26)\end{array}$ & NS \\
\hline $\begin{array}{c}\text { CD25+ Foxp3+ } \\
\text { CD4+ T cells } \\
\text { (\% of CD4+T cells) }\end{array}$ & $\begin{array}{l}7.94 \pm 1.04 \\
(3.6 \text { to } 16)\end{array}$ & $\begin{array}{l}8.2 \pm 0.61 \\
(4 \text { to } 14.4)\end{array}$ & $\begin{array}{l}8.72 \pm 0.7 \\
(2.9 \text { to } 13.5)\end{array}$ & NS \\
\hline Intracellular CTLA-4 in CD4+ T cells (\%) & $\begin{array}{l}4.35 \pm 1.10 \\
(1 \text { to } 13.3)\end{array}$ & $\begin{array}{l}2.51 \pm 0.40 \\
(0 \text { to } 5.9)\end{array}$ & $\begin{array}{l}1.35 \pm 0.48^{*}, \S \\
(0 \text { to } 7.5)\end{array}$ & $\begin{array}{c}0.005(\mathrm{KW}) \\
\text { RA vs HC } 0.003 \\
\text { SpA vs HC NS } \\
\text { RA vs SpA } 0.02\end{array}$ \\
\hline Intracellular CTLA-4 in CD4+ Treg (\%) & $\begin{array}{l}2.76 \pm 0.44 \\
(0.5 \text { to } 6.3)\end{array}$ & $\begin{array}{l}1.88 \pm 0.34 \\
\quad(0 \text { to } 5)\end{array}$ & $\begin{array}{l}0.90 \pm 0.32^{*}, \S \\
\quad(0 \text { to } 3.9)\end{array}$ & $\begin{array}{c}0.007(\mathrm{KW}) \\
\text { RA vs HC } 0.0045 \\
\text { SpA vs HC NS } \\
\text { SpA vs RA } 0.027\end{array}$ \\
\hline$\underset{(\%)}{\text { Intracellular CTLA-4 in Activated CD4+ T cells }}$ & $\begin{array}{l}1.59 \pm 0.72 \\
(0 \text { to } 7)\end{array}$ & $\begin{array}{l}0.63 \pm 0.26 \\
\quad(0 \text { to } 5)\end{array}$ & $\begin{array}{l}0.5 \pm 0.29 \\
(0 \text { to } 5)\end{array}$ & NS \\
\hline Intracellular CTLA-4 in CD8+ T cells (\%) & $\begin{array}{l}2.03 \pm 0.57 \\
(0.4 \text { to } 7)\end{array}$ & $\begin{array}{l}2.64 \pm 0.32 \\
(0 \text { to } 6.3)\end{array}$ & $\begin{array}{l}3.49 \pm 0.88 \\
(0.1 \text { to } 13.7)\end{array}$ & NS \\
\hline Intracellular CTLA-4 in CD3- lymphocytes (\%) & $\begin{array}{l}0.89 \pm 0.72 \\
(0 \text { to } 8)\end{array}$ & $\begin{array}{l}0.67 \pm 0.21 \\
(0 \text { to } 3.3)\end{array}$ & $\begin{array}{l}3.50 \pm 0.77^{\star}, \S \\
(0 \text { to } 11)\end{array}$ & $\begin{array}{c}0.0025(\mathrm{KW}) \\
\text { RA vs HC } 0.0077 \\
\text { SpA vs HC NS } \\
\text { SpA vs RA: } 0.0017\end{array}$ \\
\hline $\begin{array}{l}\text { Intracellular CTLA-4 in the lymphocyte gate } \\
\text { (total lymphocytes) (\%) }\end{array}$ & $\begin{array}{l}7.27 \pm 1.27 \\
(1.4 \text { to } 15)\end{array}$ & $\begin{array}{l}3 \pm 0.48 \\
(0 \text { to } 7.6)\end{array}$ & $\begin{array}{l}6.89 \pm 1.3 \S \\
(0.1 \text { to } 19.3)\end{array}$ & $\begin{array}{c}0.004(\mathrm{KW}) \\
\text { RA vs HC } 0.0045 \\
\text { SpA vs HC NS } \\
\text { SpA vs RA } 0.007\end{array}$ \\
\hline
\end{tabular}

Percentage of intracellular CTLA-4 was determined by flow cytometry. Results are expressed as mean \pm standard error of the mean, (range). The Kruskal-Wallis (KW) test was used to compare T cell subsets and intracellular CTLA-4 expression in the three groups. Then, Mann-Whitney U-test was used to calculate the exact $P$ values between two groups.

$\mathrm{HC}=$ healthy controls; HLA = Histocompatibility Leukocyte Antigen; KW= Kruskal-Wallis; MW = Mann-Whitney; NS = not significant; RA = rheumatoid arthritis; $\mathrm{SpA}=$ spondylarthropathie.

patients compared with healthy controls or SpA $(P<0.01)$. This increase of intracellular CTLA-4 in CD3-negative cells of RA patients leads to an increase of total intracellular CTLA-4 when considering all the lymphocytes $(P=0.004)$, while no difference was observed between SpA patients and healthy controls in these cells. Thus, increase of circulating sCTLA-4 in patients with $\mathrm{SpA}$ did not reflect an increase of intracellular CTLA-4 (independent on the examined T cell population). This prompted us to complete our analysis by evaluating the different $C T L A-4$ transcripts.

\section{Analysis of CTLA-4 full length and spliced mRNA transcripts}

The pool of PBL from the 15 healthy donors was used as a reference. In patients with $\mathrm{SpA}$, we observed an increase expression of the spliced CTLA-4 mRNA transcript (mean \pm SEM, range, $1.608 \pm 0.2,0.09$ to 4.14 ) relative to the full form (Figure 4 ; mean \pm SEM, range, $0.942 \pm 0.11,0.03$ to $2.3, P=$ $0.0014)$. Conversely, there was no difference in the expression of the full length form versus the spliced form in patients with RA (mean \pm SEM, range, $1.117 \pm 0.28,0.1$ to 2.7 for the spliced form transcript $v s .1 .157 \pm 0.4,0.13$ to 4.59 for the full length transcript expression, $P=0.7)$. We also found a tendency for a correlation between spliced CTLA-4 mRNA tran- 

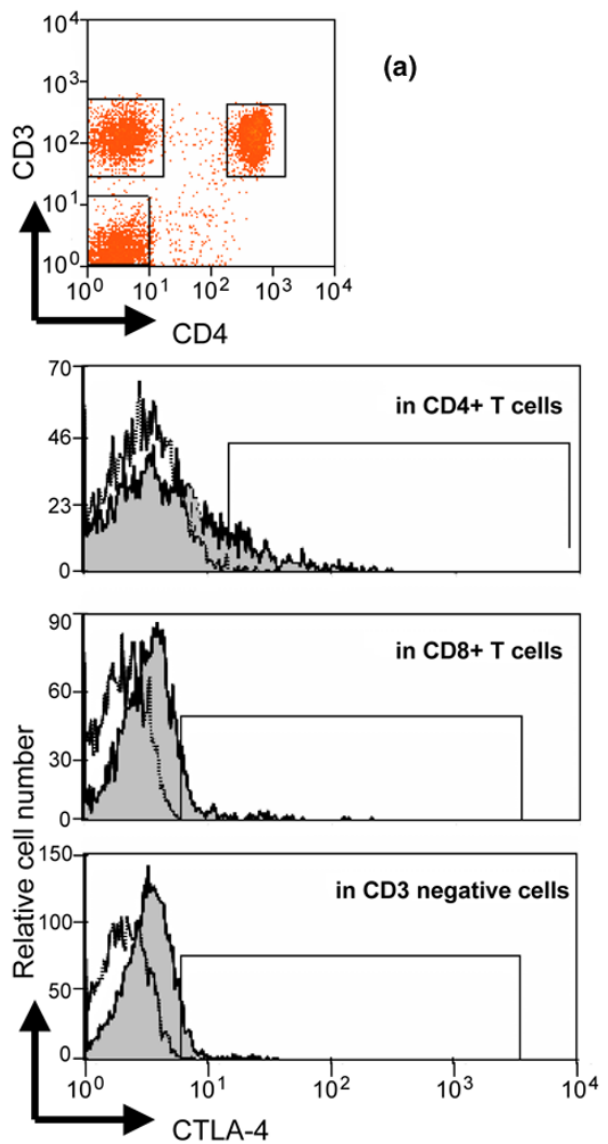
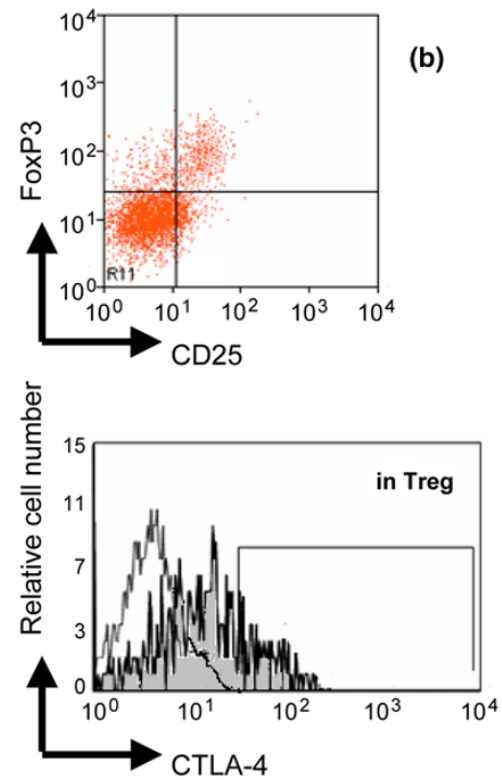

Representative analysis of intracellular Cytotoxic T Lymphocyte Antigen- 4 (CTLA-4) expression in peripheral blood lymphocyte subsets. This analysis was performed by flow cytometry as described in the Material \& Methods section. (a) CD4+ T cells, CD8+ T cells and CD3- cells were identified in the PE-CY7 fluorescence vs allophycocyanin fluorescence gate based on the expression of CD3 and CD4 (CD4+ T cells, gate R6), of only CD3 (CD8+ T cells, gate R7), of neither CD3 nor CD4 (CD3- cells, gate R4). Then, intracellular expression of CTLA-4 was determined on these cell populations by comparing PE-conjugated isotype control antibody staining (open curves) with PE-conjugated anti-CD152 monoclonal antibody staining (gray filled curves). (b) Using the same gating strategy (CD3 vs CD4 dot plot), Treg were analyzed using FoxP3 vs CD25 dot plot. Intracellular CTLA-4 expression was also determined on CD3+ CD4+ CD25+ FoxP3+ cells by comparing PE-conjugated isotype control antibody staining (open curves) with PE-conjugated anti-CD152 (CTLA-4) monoclonal antibody staining (gray filled curves). The same analysis was performed for activated (CD3+ CD4+ HLA-DR+) T cells (data not shown). An example of intracellular CTLA-4 expression in CD4+ T cells, CD8+ T cells (defined as CD3+ CD4-), CD3- cells and Treg obtained with such gating strategy for a patient with spondylarthropathy is shown.

script levels and serum sCTLA-4 in patients with $\mathrm{SpA}(r=$ $0.43, P=0.07$; Figure 5). No similar correlation was observed in the RA group. Altogether, these data suggest that the increase of sCTLA-4 found in SpA patient serum could be related to an increase of spliced CTLA-4 mRNA transcripts.

\section{Discussion}

Here, we evaluated circulating sCTLA-4 as a marker of disease activity for SpA. The role of sCTLA-4 is still not completely understood in contrast to membrane-bound CTLA-4, a negative regulator of $\mathrm{T}$ cell functions $[8,9]$. sCTLA-4 - resulting from an alternative transcript of the CTLA-4 gene $[11,12]$ - is also able to bind CD80 and CD86 and may prevent membrane-bound CTLA-4 or CD28 interactions with their ligands [12]. Thus, sCTLA-4 may interfere with both (CD28-mediated) activating and (CTLA-4-mediated) inhibitory signaling path- ways. The role of SCTLA-4 in T cell responses and inflammatory diseases have been recently highlighted by the description of the association of CTLA-4 gene polymorphisms (49 G/G and CT60 G/G) with the risk for common autoimmune diseases, such as Graves' disease, autoimmune hypothyroidism, and type I diabetes [18]. The CTLA-4 CT60G/G genotype was associated with lower $S C T L A-4$ transcript abundance in CD4+ T cells [17]. Despite the absence of SCTLA-4 protein analysis, these data by Ueda and colleagues [18] suggest that reduced SCTLA-4 (at least in CD4+ $T$ cells) is associated with increased $T$ cell activation and thereby autoreactivity.

On the contrary, further studies on circulating sCTLA-4-analyzed by ELISA- in several autoimmune diseases showed high levels of serum sCTLA-4 in patients with Graves' disease [13], 


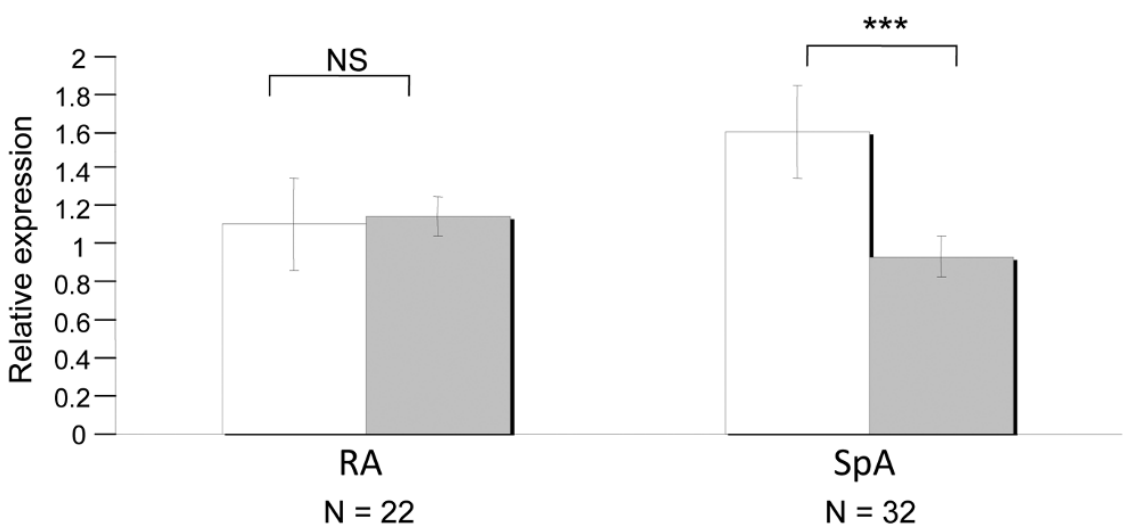

Full length CTLA-4 mRNA

Spliced form CTLA-4 mRNA

Relative expression of the 2 Cytotoxic T lymphocyte Antigen-4 (CTLA-4) transcripts, the full length form and the spliced form in peripheral blood lymphocytes of patients with spondylarthropathies (SpA) and patients with rheumatoid arthritis (RA). The full length form (gray bars) contains four exons and codes for the CTLA-4 molecule expressed at the cell membrane while the spliced form (open bars) contains three exons, lacks the transmembrane region and codes for the soluble CTLA-4 molecule [8]. Results (mean \pm standard error of the mean) are obtained using the $\Delta \Delta \mathrm{Ct}$ method and expressed as a fold change of each CTLA-4 transcript comparative with the reference obtained with the pool of 15 healthy donor PBL. Wilcoxon test was used to compare the relative production of the full length and the spliced form in patients with $\mathrm{SpA}$ and in patients with RA ${ }^{* \star *} P<$ 0.005). NS = not significant.

Hashimoto thyroiditis [13], myasthenia gravis [14], SLE $[15,16]$, and systemic sclerosis [17]. In SLE, elevated serum sCTLA-4 levels were correlated with the clinical index of disease activity SLEDAI in one study [16], but not in a second [15]. In systemic sclerosis, patients exhibited high levels of serum sCTLA-4 that correlated with disease activity [16]. In addition, sCTLA-4 was associated with cutaneous extension of fibrosis and tended to decrease in parallel to skin sclerosis improvement in a longitudinal analysis of some patients [17]. Taken together, these results suggest that high levels of circulating sCTLA-4 are observed in several autoimmune diseases and can be associated with disease severity and activity. This argues for a role of SCTLA-4 in enhancing T cell activation or preventing $T$ cell regulation, leading finally to exacerbation of the disease $[16,17]$.

The main finding of our study is that there are increased levels of serum sCTLA-4 in patients with SpA, compared with levels observed in patients with RA or in healthy volunteers. Circulating SCTLA-4 correlated with clinical index of disease activity BASDAI and CRP levels. As previously reported [12-15], serum SCTLA-4 was very low in our group of healthy controls, even in the 24 positive HLA-B27 subjects. We also confirm that patients with SLE had high circulating SCTLA-4 levels (around 70-fold more than control subjects). Our cohort of patients included mainly AS and undifferentiated SpA, but we did not observed significant differences between SpA subgroups (data not shown). As expected, the majority of patients with SpA expressed the HLA-B27 antigen, but again, this had no influence on the levels of SCTLA-4. In addition, no correlation was found between SCTLA-4, age, or the clinical charac- teristics of the patients. However, we found that male patients had higher sCTLA-4 levels than female patients but this may be explained by a predominance of male patients with $\mathrm{SpA}$ (73.3\% in our series).

Our patients had conventional treatments for SpA (i.e. mainly NSAIDs) and a limited number of patients had a second-line treatment. However, it is considered that these treatments had no influence on $T$ cell activation and costimulation pathways and therefore on the level of sCTLA-4. Eight SpA patients among the 165 analyzed here received oral prednisolone. Corticosteroids have been shown to decrease membrane CTLA4 expression after human T cell activation [27]. Moreover, oral prednisolone in asthmatic patients has been shown to reduce serum sCTLA-4 concentrations after two weeks of treatment [28]. However, this can not be evaluated in our cohort because the number of patients on prednisolone is very low and concentrations are different $(<10 \mathrm{mg} /$ day in our study vs $30 \mathrm{mg} /$ day [28]). The impact of therapy on circulating sCTLA4 is an interesting question to address.

The increase of sCTLA-4 in the serum of our patients with SpA contrasted with a normal percentage of cells positive for intracellular CTLA-4 (in comparison with the percentage found in healthy controls), suggesting a preferential expression of the spliced form of the CTLA-4 gene. Indeed, CTLA-4 mRNA analysis confirms this hypothesis because the spliced CTLA4 RNA transcripts were found to be expressed at a higher level compared with the full length form. These results indicate that SpA patients had a high production of sCTLA-4 which was related to a preferential transcription of the CTLA-4 mRNA 
Figure 5

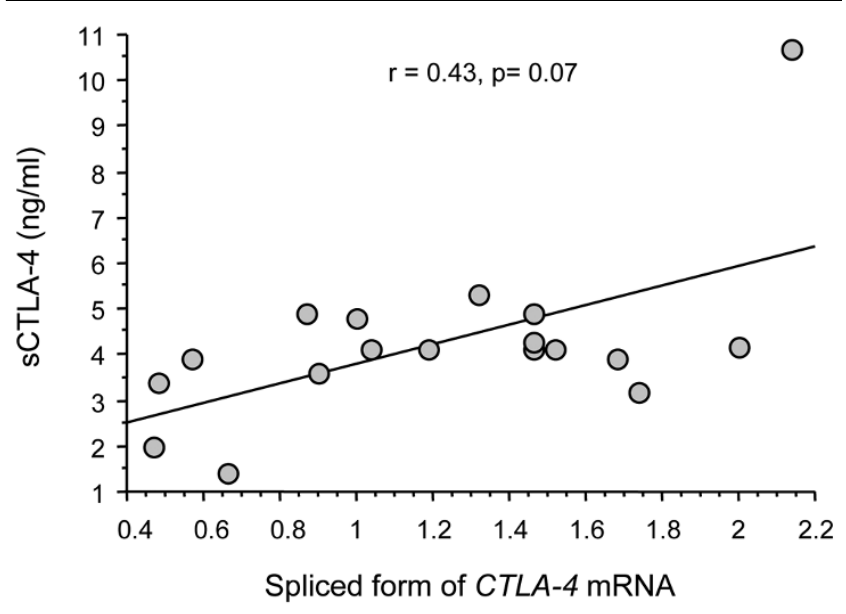

Correlation between serum concentrations of soluble Cytotoxic T Lymphocyte Antigen-4 (sCTLA-4, expressed in $\mathrm{ng} / \mathrm{ml}$ ) and the spliced form of CTLA-4 transcript expression (spliced form of the CTLA-4 mRNA, analyzed in PBL and expressed as a fold change comparative with the reference obtained with the pool of 15 healthy donor $\mathrm{PBL}$ ). This spliced form of the CTLA-4 transcript encodes for the soluble CTLA-4 molecule. The statistical test used was Spearman's $r$ test.

spliced form. The reason for the main expression of these CTLA-4 transcripts in SpA is not known but one may hypothesize that genetic background could play a role [18]. However, our cohort to date did not include a sufficient number of patients to appreciate the relation between circulating sCTLA4, CTLA-4 mRNA spliced form, and CTLA-4 polymorphism.

SpAs are characterized by an infiltration of the sacroiliac joints, the synovium and entheseal structures by inflammatory cells. Different cells are found in these lesions [4,5]. Both CD4+ and CD8+ T lymphocytes are described at the pathological sites as well as $B$ cells and macrophages $[4,5]$. These infiltrated $T$ cells are activated and require the active participation of costimulation pathways. Thus, a high production of sCTLA-4 in $\mathrm{SpA}$ may potentially influence immune responses. As stated above, sCTLA-4 may block the down regulation of activated T cells mediated by CTLA-4-CD80/CD86 interactions, enhancing immune response in situ. Costimulation pathways have not been previously evaluated in SpA. However, in the HLA-B27 transgenic rat model of $\mathrm{SpA}$, a decrease in formation of conjugates between dendritic cells expressing HLA-B27 and T cells was observed [29]. This decrease in dendritic cell-T cell conjugates was not related to a decrease of CD80 or CD86 expression, but resulted from a defective CD86 costimulatory pathway [29]. One may speculate that this defective APC function is due to the blockade of CD86 by sCTLA-4.

Treg are also implicated in the inflammatory response in SpA. Treg were found to be enriched in synovial tissues from patients with $\mathrm{SpA}$, contrasting with a low percentage of Treg in the blood compartment [30]. In our study, we did not observe a significant reduction in the percentage of circulating
Treg in our SpA patients as compared with healthy controls and RA patients. Treg constitutively expressed CTLA-4 [8] and suppressive functions of some Treg subsets are dependent on CTLA-4 [10,31]. Thus, one may speculate that a high production of sCTLA-4 in SpA may interfere with Treg functions, leading to a sustained and/or enhanced immune response. As stated above, the relation between SCTLA-4 and disease activity in different autoimmune diseases argues for a blockade of the inhibitory signal resulting from CTLA-4/CD80CD86 binding.

In this study, serum sCTLA-4 was found mildly elevated in patients with RA compared with healthy controls. In addition, the percentage of cells positive for intracellular CTLA-4 was found decreased in CD4+ T cells and also in Treg. These results were not explained by the relative lymphopenia that characterized our RA patients, which involved CD3+ T cells and CD8+ T cells, while CD4+ T cells and Treg did not differ between patients and controls. On the other hand, intracellular CTLA-4 was found increased in the CD3-negative cell population, presumably $B$ cells. Finally, there was no preferential expression of CTLA-4 transcripts in RA. Altogether, these results suggest that patients with RA had mild elevation of SCTLA-4 that may result from an increased expression of CTLA-4 in 'non T' cell subsets. RA is a chronic joint disease characterized by a major infiltration of the synovium by $T$ cells. These cells are activated with the main implication of the CD28/CTLA-4 - CD80/CD86 ligand pairs. Altered cell surface expression of CD28, CTLA-4, CD80, and CD86 has been described in RA [32]. Thus, high levels of sCTLA-4 (whatever the producing cell was) may sustain T cell activation leading to inflammation and 'autoaggression', as observed in other autoimmune diseases. Reduced CTLA-4 expression in Treg can be related to defective function previously reported in RA [33,34]. A recent study reports that diminished CTLA-4 expression by Treg from RA patients was related to an increase rate of CTLA-4 internalization after activation [34].

\section{Conclusions}

Similar to other autoimmune diseases $[16,17], \mathrm{SpA}$ are characterized by high serum SCTLA-4 levels with a significant and positive correlation with disease activity. These high levels of circulating sCTLA-4 in SpA were not explained by altered intracellular expression of CTLA-4, but by a preferential expression of the spliced form of CTLA-4 transcripts, a result that was not observed in RA. This suggests a potential immunologic role for sCTLA-4 in SpA. These results also indicate that SCTLA-4 could potentially be used as a surrogate marker for measuring disease activity in SpA.

Finally, the implication of sCTLA-4 in SpA also suggests the potential use of agents blocking costimulation pathways in this group of disorders. Indeed, a recent manuscript reports the use of abatacept - the fusion protein associating the CTLA-4 extracellular domain and the constant fragment region of 
human $\lg \mathrm{G} 1$ and blocking CD28/CD80-CD86 costimulatory pathway- in a patient with undifferentiated SpA. After 12 months of treatment with abatacept, the patient was in complete remission [35].

\section{Competing interests}

The authors declare that they have no competing interests.

\section{Authors' contributions}

ET is the main investigator who conceived and designed the study and drafted the manuscript. He contributed to the recruitment of the patients involved in the study, analyzed the Results, and performed the statistical analysis. PS is responsible for laboratory parameter assessment. He contributed to the preparation of the manuscript by writing the Methods section. He analyzed and contributed to the discussion of the results. MD performed CTLA-4 transcript analysis, supervised sample collection, ELISA, and cytometry analysis. LP collected samples and performed flow cytometry experiments, ELISA. SP supervised cytometry and analyzed cytometry results. FP participated to the study by recruiting healthy controls (platelets donors) including HLA-B27 positive subjects. JC selected the HLA-B27 positive healthy donors among platelet donors. PT is the director of EFS Bourgogne Franche-Comté and of INSERM UMR645 University of Franche-Comté. He contributed to the discussion of the results. DW is the head of the Department of Rheumatology and contributed to the work as a clinical investigator. All authors read and approved the final manuscript.

\section{Acknowledgements}

This work was supported by a grant from «La Société Française de Rhumatologie» (E. Toussirot), «'Association Franc-Comtoise pour la recherche, l'enseignement en rhumatologie" (E. Toussirot) and le CIC-

Biotherapy 506, University Hospital Besançon (L. Perrot). We thank Idir Idirène, Maryse Billot, Christine Colombain, Céline Pagneux Eléonore Gravelin, and Amélie Verdot for expert technical assistance.

\section{References}

1. Calin A: Terminology, introduction, diagnostic criteria, and overview. In The spondylarthritides Edited by: Calin A, Taurog JD. Oxford: Oxford University Press; 1998:1-15.

2. Hammer RE, Maika SD, Richardson JA, Tang JP, Taurog JD: Spontaneous inflammatory disease in transgenic rats expressing HLA-B27 and human $\beta 2$ microglobulin: an animal model of HLA-B27 associated disorder. Cell 1990, 63:1099-1112.

3. Pachebo-Tena C, Zhang X, Stone M, Burgos-Vargas R, Inman R: Innate immunity in host-microbial interactions: beyond B27 in the spondylarthropathies. Curr Opin Rheumatol 2002, 14:373-382.

4. Baeten D, Demetter P, Cuvelier C, Van Den Bosch, Kruithof E, Van Damme N, Verbuggen G, Mielants H, Veys EM, De Keyser F: Comparative study of the synovial histology in rheumatoid arthritis, spondylarthropathy, and osteoarthritis: influence of disease duration and activity. Ann Rheum Dis 2000, 59:945-953.

5. Laloux L, Voisin MC, Allain J, Martin N, Kerboull L, Chevalier X, Claudepierre P: Immunohistological study of entheses in spondylarthropathies: comparison in rheumatoid arthritis and osteoarthritis. Ann Rheum Dis 2001, 60:316-321.

6. Toussirot E, Wendling D: The immunogenetics of ankylosing spondylitis. Rev Med Interne 2006, 27:762-771.

7. Lenschow DJ, Walunas TL, Bluestone JA: CD28/B7 system of T cell costimulation. Annu Rev Immunol 1996, 14:233-258.
8. Teft WA, Kirchhof MG, Madrenas J: A molecular perspective of CTLA-4 function. Annu Rev Immunol 2006, 24:65-97.

9. Carreno BM, Bennett F, Chau TA, Ling V, Luxenberg D, Jussif J, Baroja ML, Madrenas J: CTLA-4 (CD152) can inhibit T cell activation by two different mechanisms depending on its level of cell surface expression. $J$ Immuno/ 2000, 165:1352-1356.

10. Wing $K$, Onishi $\mathrm{Y}$, Prieto-Martin $\mathrm{P}$, Yamaguchi $\mathrm{T}$, Miyara $\mathrm{M}$, Fehervari Z, Nomura T, Sakaguchi S: CTLA-4 control over Foxp3+ regulatory T cell function. Science 2008, 322:271-275.

11. Oaks M, Hallett K, Penwell RT, Stauber EC, Warren SJ, Tector AJ: A native soluble form of CTLA-4. Cell Immunol 2000 201:144-153.

12. Pawlak E, Kochanowska IE, Frydecka I, Kielbinski M, Potoczek S, Bilinska M: The soluble CTLA-4 receptor: a new marker in autoimmunes diseases. Arch Immunol Ther Exp (Warsz) 2005, 53:336-341.

13. Oaks MK, Hallett KM: Cutting edge: a soluble form of CTLA-4 in patients with autoimmune thyroid disease. J Immunol 2000, 164:5015-5018.

14. Wang XB, Kakuolidou M, Giscombe R, Qiu Q, Huang DR, Pirskanen R, Lefvert AK: Abnormal expression of CTLA-4 by T cells from patients with myasthenia gravis: effect of an AT-rich sequence. J Neuroimmunol 2002, 130:224-232.

15. Liu MF, Wang CR, Chen PC, Fung LL: Increased expression of soluble cytotoxic $T$ lymphocyte associated antigen- 4 molecule in patients with systemic lupus erythematosus. Scand Immunol 2003, 57:568-572.

16. Wong CK, Lit LCW, Tam LS, Li EK, Lam CWK: Aberrant production of soluble costimulatory molecules CTLA-4, CD28, CD80 and CD86 in patients with systemic lupus erythematosus. Rheumatology 2005, 44:989-994.

17. Sato $S$, Fujimoto $M$, Hasegawa $M$, Komura $K$ Yanaba $K$, Hayakawa I, Matsushita T, Takehara K: Serum soluble CTLA-4 levels are increased in diffuse cutaneous systemic sclerosis. Rheumatology 2004, 43:1261-1266.

18. Ueda H, Howson JM, Esposito L, Heward J, Snook H, Chamberlain G, Rainbow DB, Hunter KM, Smith AN, Di Genova G, Herr MH Dahlman I, Payne F, Smyth D, Lowe C, Twells RC, Howlett S, Healy B, Nutland S, Rance HE, Everett V, Smink LJ, Lam AC, Cordell HJ, Walker NM, Bordin C, Hulme J, Motzo C, Cucca F, Hess JF, et al:: Association of T cell regulatory gene CTLA-4 with susceptibility to autoimmune disease. Nature 2003, 423:506-511.

19. Dougados $M$, Linden $S$ van der, Juhlin $R$, Huitfeldt $B, A m o r ~ B$, Calin A, Cats A, Dijkmans B, Olivieri I, Pasero G: The European Spondylarthropathy Study Group preliminary criteria for the classification of spondylarthropathy. Arthritis Rheum 1991, 34:1218-1227.

20. Garrett $P$, Jenkinsson $T$, Kennedy LG, Whitelock H, Gaisford $P$, Calin A: A new approach to defining disease status in ankylosing spondylitis: the Bath Ankylosing Spondylitis Disease Activity Index. J Rheumatol 1994, 21:2286-2291.

21. Calin A, Garrett S, Whitelock H, Kennedy LG, O'Hea J, Mallorie P, Jenkinson $\mathrm{T}$ : A new approach to defining functional ability in ankylosing spondylitis: the development of the Bath Ankylosing Spondylitis Functional Index (BASFI). J Rheumatol 1994 21:2281-2285.

22. Arnett FC, Edworthy SM, Bloch DA, McShane DJ, Fries JF, Cooper NS, Healey LA, Kaplan SR, Liang MH, Luthra HS: The American Rheumatism Association 1987 revised criteria for the classification of rheumatoid arthritis. Arthritis Rheum 1988, 31:315-324.

23. Tan EM, Cohen AS, Fries JF, Masi AT, McShane DJ, Rothfield NF, Schaller JG, Talal N, Winchester RJ: The 1982 revised criteria for the classification of systemic lupus erythematosus. Arthritis Rheum 1982, 25:1271-1277.

24. Reimann KA, O'Gorman MR, Spritzler J, Wilkening CL, Sabath DE, Helm K, Campbell DE: Multisite comparison of CD4 and CD8 Tlymphocyte counting by single- versus multiple-platform methodologies: evaluation of Beckman Coulter flow-count fluorospheres and the tetraONE system. The NIAID DAIDS New Technologies Evaluation Group. Clin Diagn Lab Immunol 2000, 7:344-351.

25. Tran DQ, Ramsey $\mathrm{H}$, Shevach EM: Induction of FOXP3 expression in naive human CD4+FOXP3 $\mathrm{T}$ cells by $\mathrm{T}$-cell receptor stimulation is transforming growth factor-beta dependent but does not confer a regulatory phenotype. Blood 2007, 110:2983-2990. 
26. Pfaffl MW: A new mathematical model for relative quantification in real-time RT-PCR. Nucleic Acids Res 2001, 29:e45.

27. Agarwal SK, Marshall GD Jr: Role of CD28/B7 costimulation in the dexamethasone-induced suppression of IFN-gamma. J Interferon Cytokine Res 2000, 20:927-934.

28. Oin XJ, Shi HZ, Qin SM, Kang LF, Huang CP, Zhong XN: Effects of allergen inhalation and oral glucocorticoid on serum soluble CTLA-4 in allergic asthmatics. Allergy 2005, 60:774-779.

29. Hacquard-Bouder C, Flagarone G, Bosquet A, Smaoui F, Monnet $D$, Ittah M, Breban M: Defective costimulatory function is a striking feature of antigen presenting cells in an HLA-B27 transgenic rat model of spondylarthropathy. Arthritis Rheum 2004, 50:1624-1635.

30. Cao D, Van Vollenhoven R, Klareskog L, Trollmo C, Malmstrom V: CD25 bright CD4+ regulatory $T$ cells are enriched in inflamed joints of patients with chronic rheumatic disease. Arthritis Res Ther 2004, 6:R335-346.

31. Manzotti CN, Tipping H, Perry LC, Mead KI, Blair PJ, Zheng Y, Sansom DM: Inhibition of human T cell proliferation by CTLA-4 utilizes CD80 and requires CD25+ regulatory cells. Eur J Immunol 2002, 32:2888-2896.

32. Liu MF, Kohsaka H, Sakurai H, Azuma M, Okumura K, Saito I, Miyasaka N: The presence of costimulatory molecules CD86 and CD28 in rheumatoid arthritis synovium. Arthritis Rheum 1996, 39:110-114.

33. Ehrenstein MR, Evans JG, Singh A, Moore S, Warnes G, Isenberg $D A$, Mauri C: Compromised function of regulatory $T$ cells in rheumatoid arthritis and reversal by anti-TNF alpha therapy. J Exp Med 2004, 200:277-285.

34. Flores-Borja F, Jury EC, Mauri C, Ehrenstein MR: Defects in CTLA-4 are associated with abnormal regulatory $T$ cell function in rheumatoid arthritis. Proc Natl Acad Sci USA 2008, 105:19396-19401.

35. Olivieri I, D'Angelo S, Mennillo GA, Pistone G, Scarano E, Padula A: Abatacept in spondyloarthritis refractory to tumour necrosis factor alpha inhibition. Ann Rheum Dis 2009, 68:151-152. 